\title{
Characterization of tonsil infiltration and gene expression profile of innate sensors in PFAPA patients
}

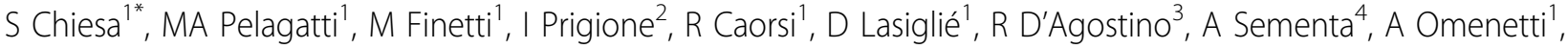 \\ E Traggiai', A Martini ${ }^{1}$, M Gattorno'
}

From 18th Pediatric Rheumatology European Society (PReS) Congress

Bruges, Belgium. 14-18 September 2011

\section{Background}

PFAPA syndrome is a common cause of periodic fever during early childhood belongs to the auto-inflammatory diseases. Palatine tonsils (PT) are sites where innate immunity leads to onset of the adaptive immunity, mediated by $\mathrm{B}$ and $\mathrm{T}$ lymphocytes. Three families of pathogen sensors mediate the recognition of microbes: Toll-like receptors (TLRs), NOD-like receptors (NLRs) and RIG-I-like receptors (RLRs).

\section{Aim}

We aimed to investigate differences in leucocytes subpopulations and innate receptors gene expression of tonsils cells and peripheral blood (PB) from PFAPA patients to understand the pathogenesis of this disease.

\section{Methods}

Tonsil tissue and $\mathrm{PB}$ were obtained from pediatric patients undergoing tonsillectomy: PFAPA patients $(n=12)$ and control group, CG $(n=15)$.We performed staining of subpopulations on tonsils cells and tissues using flow cytometry and immunohistochemistry. We analyzed TLRs, NLRs, and RLRs gene expression by quantitative RT-PCR.

\section{Results}

The histology of tonsils in PFAPA showed a preservation of tonsillar architecture without specific chronic inflammation with respect to CG. Preliminary results demonstrate an higher number of naïve CD4 and CD8 $\mathrm{T}$ cells and a significantly lower percentage of both effector memory $\mathrm{T}$ cells and functional Foxp3 $\mathrm{T}$ reg in PFAPA patients compared to CG. Then, we observed an increase NK cells in PFAPA patients with respect to CG. Tonsil cells expressed a broad repertoire of TLRs in PFAPA vs CG. The gene expression analysis of NLRs and RLRs receptors is ongoing.

\section{Conclusions}

Results indicate a possible crucial role of NK cells and TLRs receptors during immune response in PFAPA patients. In addition, the high numbers of undifferentiated naïve $\mathrm{T}$ cells in PFAPA patients provide support for probable involvement of the adaptive immunity.

\section{Author details}

${ }^{1}$ Laboratory of Immunology and Rheumatic Disease, U.O. Pediatria II, G. Gaslini Institute, Genoa, Italy, Department of Pediatrics, University of Genoa, Italy. ${ }^{2}$ Laboratory of Oncology, G.Gaslini Institute, Genoa, Italy. ${ }^{3}$ Unit of Otolaryngology, , G.Gaslini Institute, Genoa, Italy. ${ }^{4}$ Service of Pathology, G. Gaslini Institute,Genoa, Italy.

Published: 14 September 2011
* Correspondence: sabiolina@yahoo.com

${ }^{1}$ Laboratory of Immunology and Rheumatic Disease, U.O. Pediatria II, G. Gaslini Institute, Genoa, Italy, Department of Pediatrics, University of Genoa, Italy

Full list of author information is available at the end of the article (c) 2011 Chiesa et al; licensee BioMed Central Ltd. This is an open access article distributed under the terms of the Creative Commons Attribution License (http://creativecommons.org/licenses/by/2.0), which permits unrestricted use, distribution, and reproduction in any medium, provided the original work is properly cited. 